\title{
Convoy Effect Elimination in FCFS Scheduling
}

\author{
Sambath M., K. Padmaveni, Linda Joseph, Ravi S., J. Thangakumar, D. John Aravindhar
}

\begin{abstract}
One of the important activities of operating systems is process scheduling. There are many algorithms available for scheduling like First Come First Served, Shortest Job First, Priority Scheduling and Round Robin. The fundamental algorithm is First Come First Served. It has some drawback of convoy effect. Convoy effect occurs when the small processes are waiting for lengthy process to complete. In this paper novel method is proposed to reduce convoy effect and to make the Scheduling optimal which reduces average waiting time and turnaround time.
\end{abstract} time.

Keywords: convoy effect, scheduler, throughput, turnaround

\section{INTRODUCTION}

CPU Scheduling is the process of assigning the process to the processor for execution. In memory multiple programs are stored and ready for execution. The performance of the processor depends on how the programs are dispatched to the processor for execution. In First Come First Served (FCFS) algorithm the processes are dispatched in the order of arrival to the processor. Scheduling is done by the scheduler[1]. The scheduling algorithm reflects the overall performance of the processor. There are three types of schedulers: [1]

1. Long-term scheduler (Job scheduler): It is responsible for loading the programs from the memory into the ready queue.

2. Short-term scheduler (CPU Scheduler): Schedules the selected process for execution and gives control to the CPU[2].

3. Medium-term scheduler: Time sharing systems uses this kind of scheduler. The process is preempted for some reason and resumed back after sometime. [9]

Revised Manuscript Received on February 24, 2020.

* Correspondence Author

Sambath M., Assistant Professor, Department of CSE, Hindustan Institute of Technology and Science, Chennai, India.

Email: msambath@hindustanuniv.ac.in

Dr. K. Padmaveni, Associate Professor, Department of CSE, Hindustan Institute of Technology and Science, Chennai, India.

Email: kpadmaveni@hindustanuniv.ac.in

Linda Joseph, Assistant Professor, Department of CSE, Hindustan Institute of Technology and Science, Chennai, India.

Email: lindaj@hindustanuniv.ac.in

Ravi S., Assistant Professor, Department of CSE, Hindustan Institute of Technology and Science, Chennai, India.

Email: sravi@hindustanuniv.ac.in

Dr. J. Thangakumar, Associate Professor, Department of CSE, Hindustan Institute of Technology and Science, Chennai, India. Email: tkumar@hindustanuniv.ac.in

Dr. D. John Aravindhar, Professor, Department of CSE, Hindustan Institute of Technology and Science, Chennai, India.

Email: jaravindhar@hindustanuniv.ac.in

(C) The Authors. Published by Blue Eyes Intelligence Engineering and Sciences Publication (BEIESP). This is an open access article under the CC BY-NC-ND license (http://creativecommons.org/licenses/by-nc-nd/4.0/)
The performance of the scheduling algorithm is estimated based on various criteria like CPU utilization, Throughput, Turnaround time, waiting time and response time.[3]

1. CPU utilization indicates how effectively CPU is utilized.[8]

2. Throughput denotes the number of processes completed per unit time.[4]

3. Turnaround Time is the time needed for the process to complete its execution.[5]

4. Waiting Time is the amount of time a process waiting in the queue.

5. Response Time is the time between submission of request for execution and till the first response is produced not the output.

\section{FCFS SCHEDULING}

The processes are loaded from memory into ready queue. From the ready queue the processes are taken based on their arrival time and assigned to the processor for execution[6] as shown in Figure 1.

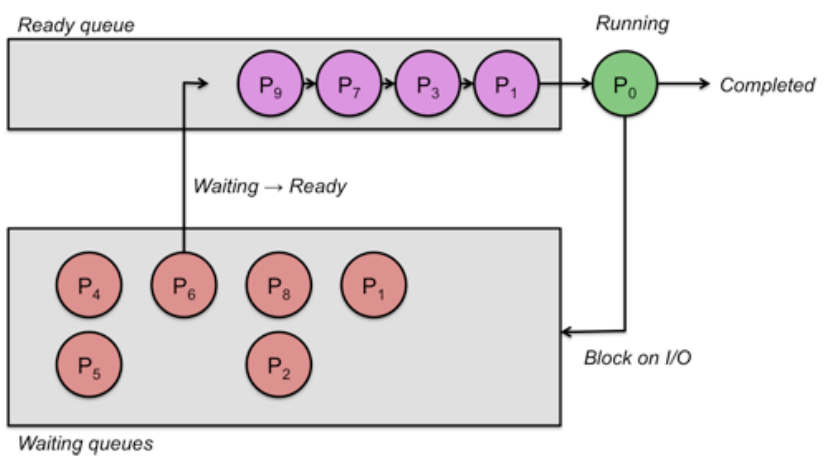

Figure 1 FCFS Scheduling

The table 1 lists the processes and their execution time (burst time). The FCFS scheduling (Figure 2) is applied and the average waiting time and turnaround time are calculated and it is listed in table 2.

Table 1 Process and burst time

\begin{tabular}{|c|c|c|}
\hline S.No. & Process & Burst Time \\
\hline 1 & P1 & 15 \\
\hline 2 & P2 & 19 \\
\hline 3 & P3 & 35 \\
\hline 4 & P4 & 40 \\
\hline 5 & P5 & 50 \\
\hline 6 & P6 & 58 \\
\hline 7 & P7 & 3 \\
\hline 8 & P8 & 5 \\
\hline 9 & P9 & 7 \\
\hline 10 & P10 & 6 \\
\hline
\end{tabular}


Convoy Effect Elimination in FCFS Scheduling

\begin{tabular}{|l|c|c|c|c|c|c|c|c|c|}
\hline P1 & P2 & P3 & P4 & P5 & P6 & P7 & P8 & P9 & P10 \\
\hline 0 & 15 & 34 & 69 & 109 & 159 & 217 & 220 & 225 & 232 \\
\end{tabular}

Figure 2 Gantt Chart using FCFS

Table 2 Waiting time and turnaround time using FCFS

\begin{tabular}{|c|c|c|c|}
\hline Process & Burst Time & Waiting time & Turnaround time \\
\hline P1 & 15 & 0 & 15 \\
\hline P2 & 19 & 15 & 34 \\
\hline P3 & 35 & 34 & 69 \\
\hline P4 & 40 & 69 & 109 \\
\hline P5 & 50 & 109 & 159 \\
\hline P6 & 58 & 159 & 217 \\
\hline P7 & 3 & 217 & 220 \\
\hline P8 & 5 & 220 & 225 \\
\hline P9 & 7 & 225 & 232 \\
\hline P10 & 6 & 232 & 238 \\
\hline & Average & $\mathbf{1 2 8}$ & $\mathbf{1 5 1 . 8}$ \\
\hline
\end{tabular}

The average waiting time is 128 unit time and average turnaround time is 151.8 unit time. From the table 2 it is observed that the short processes are available after the lengthy processes[7]. Due to this small processes are waiting till the completion of lengthy processes. This leads to increase in waiting time as well as turnaround time. This effect is called as convoy effect. To reduce this effect novel approach - BinFCFS algorithm is proposed.

\section{BINFCFS ALGORITHM}

1. Find out the minimum and maximum in burst time.

2. Create the number of bins depends on the range of burst time.

3. Group the processes and put it in the bins based on the range of burst time.

\begin{tabular}{|l|l|}
\hline \begin{tabular}{l|l|} 
Bin 0 \\
(0-9)
\end{tabular} & $\begin{array}{l}\text { Bin 1 } \\
(\mathbf{1 0 - 1 9 )}\end{array}$ \\
\hline P7 & P1 \\
P8 & P2 \\
P9 & \\
P10 & \\
\hline
\end{tabular}

4. Take the processes from the bins in the order and execute.

For the above scenario, the processes are arranged into the bins based on their burst time as shown in Figure 3. Start from Bin 0 executes P7, P8, P9 and P10. Then continue with Bin1, Bin2 and so on.

For the above scenario, the processes are arranged into the bins based on their burst time as shown in Figure 3. Start from Bin 0 executes P7, P8, P9 and P10. Then continue with Bin1, Bin2 and so on.

The waiting time and turnaround time for each process is calculated using the proposed method - BinFCFS algorithm(Figure 4) and is given in the table 3.
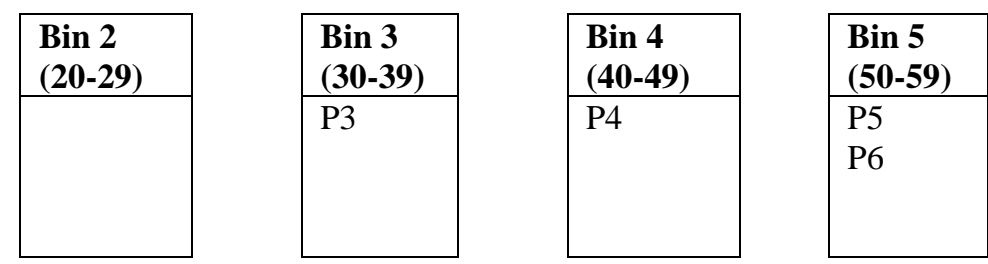

Figure 3 Bins holding the processes

\begin{tabular}{|l|l|l|l|l|l|l|l|rr|r|}
\hline P7 & P8 & P9 & P10 & P1 & P2 & P3 & P4 & P5 & P6 \\
\hline 0 & 15 & 34 & 69 & 109 & 159 & 217 & 220 & 225 & 232 \\
\end{tabular}

Figure 4 Gantt Chart using BinFCFS algorithm 
Table 3 Waiting time and turnaround time using BinFCFS

\begin{tabular}{|c|c|c|c|}
\hline Process & Burst Time & waiting time & Turnaround time \\
\hline P7 & 3 & 0 & 3 \\
\hline P8 & 5 & 3 & 8 \\
\hline P9 & 7 & 8 & 15 \\
\hline P10 & 6 & 15 & 21 \\
\hline P1 & 15 & 21 & 36 \\
\hline P2 & 19 & 36 & 55 \\
\hline P3 & 35 & 55 & 90 \\
\hline P4 & 40 & 90 & 130 \\
\hline P5 & 50 & 130 & 180 \\
\hline P6 & 58 & 180 & 238 \\
\hline & Average & $\mathbf{8 5 . 3 3}$ & $\mathbf{1 2 1 . 5}$ \\
\hline
\end{tabular}

\section{RESULT AND DISCUSSION}

The average waiting time and turnaround time for the above problem using FCFS algorithm is 128 and 151.8 as given in table 4 . It is reduced to 85.33 and 121.5 respectively using the proposed BinFCFS algorithm.

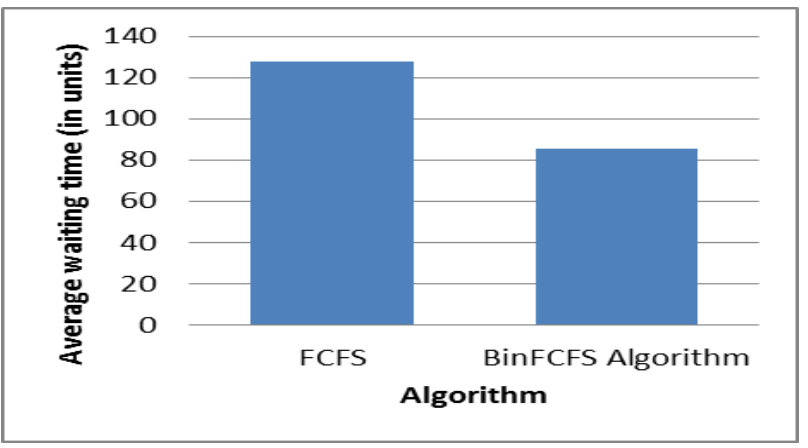

Table 4 Performance Comparison

\begin{tabular}{|l|c|c|}
\hline Algorithm & $\begin{array}{c}\text { Average } \\
\text { waiting time }\end{array}$ & $\begin{array}{c}\text { Average } \\
\text { Turnaround time }\end{array}$ \\
\hline FCFS & 128 & 151.8 \\
\hline $\begin{array}{l}\text { BinFCFS } \\
\text { Algorithm }\end{array}$ & $\mathbf{8 5 . 3 3}$ & 121.5 \\
\hline
\end{tabular}

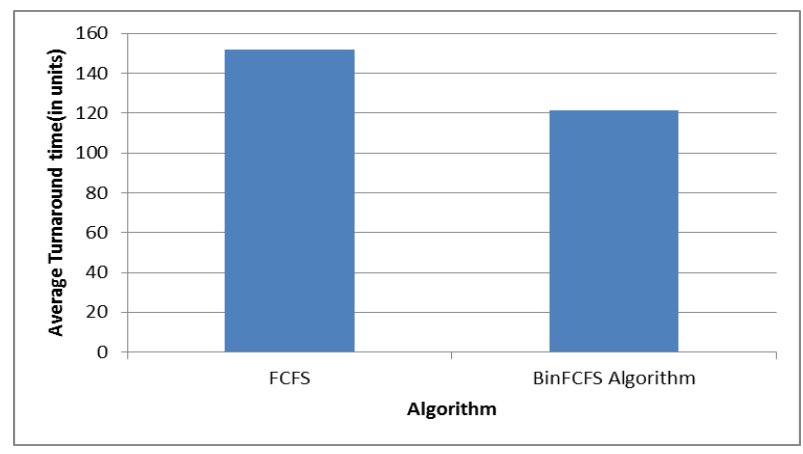

Figure 5 a) Performance comparison for Average waiting time b) Performance comparison of average turnaround time

\section{CONCLUSION}

The FCFS algorithm schedules the processes in the order of arrival irrespective of whether it is a short process or long process. Due to this convoy effect is occurred. This effect is avoided by the proposed BinFCFS algorithm by grouping the short processes and executing them in the first.

\section{REFERENCES}

1. Siahaan, Andysah Putera Utama. "Comparison analysis of CPU scheduling: FCFS, SJF and Round Robin." International Journal of Engineering Development and Research 4.3 (2016): 124-132

2. Dave, Badal, Surendra Yadav, and Manish Mathuria. "Customary Methods for CPU Scheduling: A Review." (2017).

3. Rinku, Dhruva R., and M. Asha Rani. "Evaluation of Scheduling Algorithms on Linux OS." Advances in Decision Sciences, Image Processing, Security and Computer Vision. Springer, Cham, 2020. 210-217.

4. Chandra Shekar, N., and V. Karthik. "Analysis of Priority Scheduling Algorithm on the Basis of FCFS \& SJF for Similar Priority Jobs." International Journal of Engineering Research in Computer Science and Engineering (IJERCSE) 4.3 (2017).
5. Aslam, Naila. Designing a Model for improving CPU Scheduling by using Machine Learning. Diss. 2017.

6. Sowmya, G., et al. "A Comparison Of Scheduling Algorithm For Best Utilization Of Memory." International Journal of Pure and Applied Mathematics 120.6 (2018): 3563-3570.

7. Sankar, A., and G. Ananthnath. "Improved Dynamic Time Slice Priority Scheduling Algorithm with Unknown Burst Time." (2018).

8. Joon, Monika, and Neetu Sharma. "Optimization Of Scheduling Algorithms For Load Balancing Using Hybrid Approach." (2017).

9. Abraham Silberschatz, Peter Baer Galvin and Greg Gagne, "Operating System Concepts", Ninth Edition, 2013.

\section{AUTHORS PROFILE}

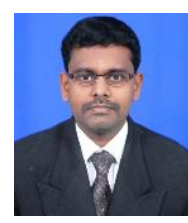

Mr. Sambath M., is graduated in Computer Science \& Engineering in the year 2001 and obtained his Master degree in Computer Science \& Engineering from Anna University in the year 2008 and currently pursuing his Ph.D. in the area of Image Processing at Hindustan Institute of Technology and Science, Chennai, India. His area of interest includes Image processing, Algorithms, Operating systems. 


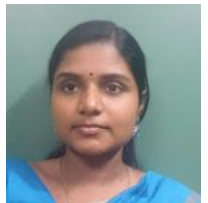

Dr. K. Padmaveni, received Ph.D. degree in cloud computing from Hindustan Institute of Technology and Science. She is currently an Associate Professor in Hindustan Institute Of Technology and Science and her main interest are in virtualization and scheduling in cloud.

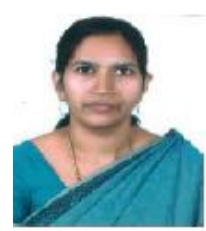

Linda Joseph, is an assistant professor at Hindustan Institute of Technology and Science, Chennai, Tamil Nadu, India. She did her masters at Noorul Islam College of Engineering, Anna University, Tamil Nadu. She is now with the Department of Computer Science and Engineering. Her research interests are Network Security, Artificial Intelligence, Virtualization and Cloud Security.

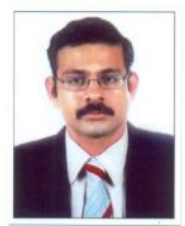

Ravi Sridharan, has received his MCA degree from SRM Engineering College, Chennai .He obtained his M.Phil Degree from Periyar University, Salem, Tamilnadu, India. He obtained his M.E., Computer Science \& Engineering from Sree Sastha Institute of Engineering \& Technology , Chennai .He is presently pursuing his Ph.D. at Hindustan Institute of Technology \& Science, Chennai, Tamil Nadu, India. He is a member of ACM, IET, IAENG ,Toast Master Club. His area of interests is Mobile Adhoc Networks, Internet of Things \& Software Engineering.

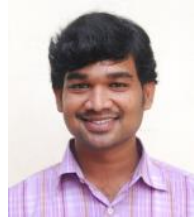

Dr. Thangakumar Jeyaprakash, has been working as an Associate Professor at Hindustan Institute of Technology and Science, Padur, Chennai in the Department of Computer Science for over Fifteen years. He has finished his Ph.D. in Computer Science and Engineering from our Institution and his research area is "Mobile Adhoc Networks and Network Security". He is professionally very competent and has the ability to motivate the students in various academic and co-curricular activities.

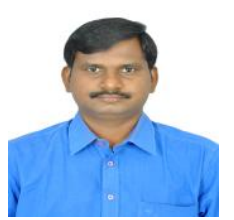

Dr. D. John Aravindhar, received Ph.D. degree in Data mining from Hindustan Institute of Technology and Science. He is currently a Professor in Computer Science Department of Hindustan Institute of Technology and Science. His area of interest are Data mining and cloud computing. 